\title{
MEMORIA HISTÓRIGA Y PENA DE MUERTE EN ESPAÑA: MELODRAMA, COMEDIA NEGRA Y DOGUMENTAL
}

\author{
Inmaculada Gordillo
}

Universidad de Sevilla

Apoderarse de la memoria y del olvido es una de las máximas preocupaciones de las clases, de los grupos, de los individuos que han dominado y dominan las sociedades históricas (Le Goff, 1991:134).

Desde diversas perspectivas y a partir de las variedades que permite la polisemia del término, la memoria resulta fuente inacabable y alimento recurrente para la creación fílmica. Comenzando con el cine que revuelve la memoria personal de los protagonistas de una determinada película, pasando por el que olfatea el álbum de recuerdos familiar a partir del legado heredado, o - en tercer lugar- el que explora la memoria mítica y fundacional, el binomio entre universo fílmico y memoria resulta prolífico y contundentemente fecundo. Pero ninguno de esos enfoques es tan actual como el que relaciona el cinematógrafo con la memoria histórica. Esta perspectiva difiere tanto de la personal como de la familiar por su implicación colectiva, y diverge de la mítica en cercanía, al rememorar unos sucesos que mantienen lazos de proximidad con el enunciatario, ya sea por cuestiones geográficas, ideológicas o generacionales.

La historia, al igual que la literatura —-polos opuestos a la hora de contemplar los diversos modelos de mundo que propuso Albaladejo-, ha constituido una fuente argumental esencial para el guión fílmico. En realidad, el cine no es una excepción entre las demás manifestaciones artísticas en su romance con la historia. Literatura, escultura, música, arquitectura, pintura, fotografía y teatro han desarrollado reflejos más o menos fieles de sucesos históricos, ya que esta disciplina ha abastecido temáticamente «desde los relatos homéricos y los monumentos conmemorativos de la antigüedad hasta la fotografía periodística pasando por la estatuaria pública y la pintura de historia» (Monterde, 2001:76). A pesar de lo incuestionable que resulta considerar la historia como fuente para el arte, no puede obviarse que existen puntos de partida diferentes que convierten a los sucesos históricos en acontecimientos discursivos, como el de Sánchez Biosca, para quien «la Historia no son los hechos acontecidos en el pasado; es 
un discurso (en realidad, un conjunto casi infinito de discursos) que trata (n) de explicarlos, conectarlos inscribiéndolos en cadenas causales que les otorgan sentido» (2006:13).

En cualquier caso, la postura de Sánchez Biosca nos resulta útil al acercarnos a la memoria histórica, formada a partir del conjunto de textos académicos, mediáticos y artísticos que organizan el imaginario generacional de una determinada sociedad. Desde hace unos años nos encontramos insertos en una serie de procesos culturales que se organizan a partir de un conjunto de elementos constantes. Uno de ellos pasa por el consumo de imágenes del periodo franquista, una vez que aumenta la distancia que nos separa temporalmente de esa época de la historia de España. Por ello, el discurso cinematográfico sobre una de las cuestiones más espinosas de nuestra historia reciente — la pena de muerte en la España de la dictadura- permitirá activar los mecanismos que el recuerdo articula para no perder de vista elementos nada edificantes de esa etapa y contraponerlo así a otros discursos donde la nostalgia es la clave.

Habría que señalar — someramente— la atracción que en todos los modos de representación narrativos de cualquier civilización ha ejercido el tema de la pena de muerte, convirtiéndolo en un motivo recurrente:

Desde los primeros momentos en los que los seres humanos pintaron, esculpieron o escribieron historias, la ejecución sumaria de una persona se convirtió en una imagen extraordinariamente atrayente para artistas y escritores. Fuente de inspiración para todos ellos, los artistas plasmaron el dramatismo del instante en el que un ser humano, o varios, se enfrenta a la muerte y al verdugo (Corral, 2005).

Así, el cine no ha escapado de esta atracción y la pena capital se ha visto reflejada en numerosas películas del cine universal: desde los primeros balbuceos del XIX y principios del XX (Exécution capitale à Berlin de Charles Pathé en 1897 e Histoire d'un crime de Ferdinand Zecca en 1901), pasando por el hito que supuso Intolerance (David W. Griffith, 1916) y el abultado número de películas de todas las nacionalidades que han desarrollado el tema hasta nuestros días (Rivaya, 2003). Dentro del cine español también puede rastrearse una buena cantidad de filmes donde de forma central o tangencial aparecen ejecuciones sumarias'.

En cualquier caso habría que subrayar la importancia del contexto de recepción de las películas —que siempre aportará elementos novedosos enriquecedores del sentido último del filme, además de las reflexiones sobre la memoria histórica- como complemento de la investigación en torno a la producción y al análisis del discurso. Así, en el año 2006, en plena efervescencia del debate sobre la reivindicación de memoria histórica del franquismo en España, Manuel Huerga estrena Salvador, un filme sobre la condena a muerte del joven Salvador Puig Antich.

La película tuvo una repercusión mediática y crítica desacostumbrada en nuestra filmografía debido a condicionamientos tanto cinematográficos como extracinematográficos. Po-

1 En 1991, por ejemplo, José Luis García Sánchez había estrenado La noche más larga, donde reflejaba los últimos fusilamientos del franquismo en septiembre de 1975, mes y medio antes de la muerte del dictador. La condena de tres militantes del Frente Revolucionario Antifascista y Patriota (FRAP), —Juan Humberto Baena, Ramón García Sanz y José Luis Sánchez Bravo_y dos de ETA —Angel Otaegui y Juan Paredes Manot-, se reconstruye a partir del encuentro — quince años más tarde- de dos abogados que participaron en el juicio. 
see una cuidada ambientación y una diferenciación de tonalidades y texturas para separar los distintos espacios y tiempos relatados. Narrativamente, el guión de Luis Arcoraza presenta dos partes bien diferenciadas: en la primera el protagonista es detenido y va narrando a su abogado las circunstancias que lo llevaron hasta la cárcel, y en la segunda — con un cambio de ritmo evidente - se relatan las últimas horas de la tensa espera hasta la negación del indulto y el cumplimiento de la pena capital. La película hará un recorrido espacial entre Francia y España y otro temporal que transitará desde 1968 a 1974, aunque no de manera cronológica. Se centra principalmente en los meses que van desde la detención de Puig Antich, el 25 de septiembre de 1973, hasta su ejecución a manos de un verdugo extremeño. En la conversación con su abogado Oriol Arau, el protagonista rememorará anécdotas y recuerdos de su labor política, su contexto familiar y afectivo.

Por un lado es incuestionable que Salvador refleja la vida del militante del Movimiento Ibérico de Liberación (MIL) que fue ejecutado en la España de la dictadura. En el dossier de prensa del filme se subraya

el valor de estar basada en hechos reales rigurosamente documentados que acontecen en un período reciente de la historia de España, el final del franquismo, una etapa relativamente virgen desde el punto de vista cinematográfico. Esto nos permite la recuperación de un escenario sociológico que apela a una memoria colectiva de amplio espectro entre el público, tanto el que vivió aquella época como también el público joven que puede encontrar elementos de identificación con el personaje, a quien verán como un rebelde con causa, anhelante y amante de una vida mejor que la que le ha tocado vivir, luchando con todas sus fuerzas contra la injusticia, la mediocridad y el conformismo.

Ciertamente hay algunos hechos históricos incuestionables recogidos fielmente por el filme de Huerga: Puig Antich fue capturado en 1973, tras un confuso tiroteo con la policía en el que el joven resulta herido y un agente muerto. Ese mismo año, el día 20 de diciembre, la organización terrorista ETA atenta contra el almirante Carrero Blanco, presidente del Gobierno de Franco, provocando su muerte. Salvador Puig Antich se convertirá en el chivo expiatorio que un sector del régimen franquista reclamó. El 2 de marzo de 1974 Puig Antich es ejecutado mediante el garrote vil en la cárcel Modelo de Barcelona.

La recuperación de una parte de nuestra memoria histórica ha sido uno de los objetivos que Manuel Huerga se marcó a la hora de elegir el tema de su segunda película. Entre las declaraciones que ofreció poco antes del rodaje destaca la siguiente afirmación:

La transición y la democracia han ensombrecido de alguna manera esos años tan importantes de lucha, esa recta final de la dictadura, la etapa que va desde mayo del 68 hasta la muerte de Franco, en que universitarios y estudiantes, jóvenes vitalistas, eligieron la clandestinidad. Todos ellos merecen esta película y yo me debo a mí mismo una revisión de todo eso [...]. La recuperación de la memoria es importante para todos los que tenemos ahora una cierta edad, pero también para esas generaciones que desconocen la lucha de tantos jóvenes contra la dictadura (García, 2005). 
Sin embargo, otros sucesos de la película están más o menos recreados, modificados, y ficcionalizados según el modelo literario en el que se basa el guión, la novela Compte enrere/ Cuenta atrás (Edicions 62 y Península), de Frances Escribano. En el libro se narran los testimonios de varias personas que conocieron a Salvador a lo largo de su vida (amigos, hermanas, compañeros de militancia en el MIL) y otros que estuvieron cerca del condenado en los últimos meses (su abogado o el funcionario de prisiones). Así se recrean las últimas horas de la existencia de Puig Antich entralazadas con una analepsis que recorre distintos momentos de su pasado: su militancia en un grupo revolucionario, su trayectoria personal y familiar. El libro —al igual que ocurrió en el rodaje del filme— va alternando el catalán y el castellano.

La publicación de la novela creó polémica por la infidelidad hacia los hechos reales. También la película fue objeto de numerosas acusaciones de inexactitud histórica, política y filosófica. Para Carles Sanz (2004:1), el filme se olvida de la posición política de Salvador Puig ante la sociedad de consumo capitalista:

Muchos de los que ignoraron su asesinato entonces, después han reivindicado a Salvador como antifranquista, revolucionario romántico, como héroe e incluso como mártir. Esa sociedad del espectáculo contra la que él luchó también intenta apropiárselo; quién no lo ha visto ya como una mercancía o como un producto mediático que vende.

También Txema Bofill, antiguo miembro de los Grupos de Acción Revolucionaria Internacionalista (GARI), señala que los errores históricos van mucho más allá de la posición ideológica del protagonista:

La estafa principal es colar esa ficción como recuperación de la memoria histórica del MIL, del anarquista Puig Antich y de las luchas de la época. Los personajes no son creíbles: ni Puig ni sus amigos estuvieron en la manifestación de Ruano; los abogados aparecen como luchadores antifranquistas cuando fueron unos completos ineptos bien pagados; los esbirros de la secreta, que eran unos chapuceros, aparecen como eficientes policías. Y Jesús Irurre, el carcelero, que pasa de torturador a revolucionario, es la más infame de las mentiras. Fue uno de los más violentos. Torturó a nuestros compañeros y lo siguió haciendo después de su ficticia conversión (García Grenzner, 2006).

Además de detalles más o menos concretos y comprobables, uno de los escollos principales de cualquier discurso — cinematográfico, periodístico o literario- que actualice y aclare elementos de la memoria histórica resulta ser el ineludible posicionamiento ideológico que impide cualquier intento de objetividad. Como señala José $M^{a}$ Pedreño, presidente del Foro por la Memoria, los aspectos humanos y culturales permiten completar muchos elementos del rompecabezas del pasado, pero «el problema comienza cuando la investigación histórica determina que el tema tratado es, también, profundamente político» (2004: 12).

Y es aquí donde la película se desliza hasta territorios que no coinciden con los hechos, incluso - para algunos - los falsean: «Reescriben y tergiversan la historia de Puig Antich haciéndole decir ETA me ha matado, que el abogado está en la misma lucha, que los amigos le comen el coco, etc. Silencian a las chicas del grupo y a Oriol Solé Sugranyes, abatido por la Guardia Civil» (García Grenzner, 2006). 
En la película de Manuel Huerga la intensidad trágica de la muerte anunciada del protagonista se viste de tonos melodramáticos en la media hora final. La duración casi escénica de los últimos momentos de la vida de Salvador Puig Antich, el sufrimiento de sus hermanas y el regodeo en los instantes más lacrimógenos de esos instantes fatales, consiguen atrapar el sentimiento del espectador de forma más folletinesca que testimonial, más efectista que documental. La fuerza dramática de la trama hubiera resultado suficientemente contundente sin necesidad de subrayar los hechos con estrategias narrativas propias del melodrama.

En cualquier caso, la película Salvador, estrenada en un momento de revisión histórica del franquismo, permite la recuperación de dos filmes realizados durante la dictadura que, desde distinta perspectiva argumental —la basculación de la focalización narrativa desde la víctima al ejecutor de la pena-y opuestos posicionamientos de género, también aluden al tema de la pena de muerte durante ese periodo histórico. El primero de ellos es una de las obras culminantes de la historia del cine español: El verdugo de Luis García Berlanga (1963). Se trata de un filme en contra de la pena de muerte con unas líneas argumentales y genéricas atípicas en la historia del cine.

Intolerencia de David W. Griffith había tratado en tres de sus cuatro historias el tema del castigo capital, fijando para siempre unos tópicos que se repetirán en muchas de las películas que giran en torno a este argumento: un asesinato poco clarificado, la detención de un sospechoso (que en muchos casos puede ser inocente), un juicio injusto o incompetente, un fallo judicial dramático y la condena a muerte, a partir de la cual se desarrolla el sufrimiento de sus familiares y amigos, las luchas para cambiar la pena, la ejecución y, en algunos casos, las carreras después de la constatación de la inocencia para detener la actuación del verdugo ${ }^{2}$. El guión de Berlanga y Azcona esquiva magistralmente esos lugares comunes y, sobre todo, elude la inflexión genérica habitual marcada —en la mayoría de los casos - con tintes dramáticos o melodramáticos. Tal vez ahí radique la fuerza de la película, donde los tonos trágicos se disfrazan de comedia esperpéntica y negra diluyendo los elementos de identificación narrativa secundaria o, lo que es lo mismo, la del espectador con algún personaje de la historia. Este distanciamiento genérico permite la contemplación de la temática de la pena de muerte desde un ángulo más crítico y desapegado, en tanto que significa una separación de la anécdota histórica concreta y dota de universalidad al argumento. Si Berlanga hubiese reflejado fielmente la muerte de los ajusticiados cuando El verdugo se estrenaba en el Festival de Venecia (el comunista Julián Grimau y los anarquistas Francisco Granados y Joaquín Delgado), seguramente no hubiese alcanzado el mismo nivel artístico. La plasmación de casos reales - con mayor o menor grado de ficcionalización-podría favorecer los argumentos a favor de la reivindicación de la memoria histórica. Sin embargo, la opción elegida por Berlanga — la plasmación de la sociedad española del franquismo a partir de la figura del verdugo- a pesar de no estar circunscrita a elementos concretos de la realidad, no deja de mostrar una clara conexión con elementos de la realidad histórica. Es innegable que el imaginario colectivo en torno al garrote vil en España se nutre, entre otros discursos, del poliédrico filme que escribieron Berlanga y Azcona. Porque «El verdugo no es sólo una película contra la pena de muerte, sino que nos sitúa ante el problema de la anulación de la voluntad individual por un magma de intereses sociales que impide cualquier libertad personal» (Maroto Laviada, 131). Este matiz convierte a la obra de 
Berlanga en un filme de doble adscripción: por un lado activa la memoria histórica gracias al reflejo social de elementos propios de la dictadura franquista; por otro, resulta una obra atemporal, que escenifica la utopía de la libertad individual más allá de unas circunstancias históricas concretas.

El distanciamiento esperpéntico y cómico de Berlanga contrasta aparentemente con la película documental Queridísimos verdugos de Basilio Martín Patino, filmada clandestinamente en diciembre de 1971, lista para exhibirse en 1973, pero censurada hasta 1977. El filme explora una oscura parcela de la realidad del momento a través del testimonio de tres verdugos supervivientes a principios de los setenta: las circunstancias de los protagonistas, la pena de muerte y las condiciones en que se aplicaba y algunos sucesos de la crónica negra de la sociedad en la que actuaban. Y remata el filme con una contundente dedicatoria: «En memoria de tanto dolor».

Temáticamente posee concomitancias importantes con los dos anteriores: recoge la noticia en prensa de la ejecución de Salvador Puig Antich ${ }^{3}$ y por otro lado, centra su atención —más que en los condenados a garrote— en los ejecutores de la pena capital. Pero el género elegido por Patino la separa de ambas tangencialmente: el documental de corte realista, basado en testimonios con sonido directo, localizaciones reales, presencia de los protagonistas de los hechos y una voz narradora que organiza el sentido de las imágenes. Podríamos pensar que, aparentemente, Patino ha elegido separarse del discurso ficcional.

Sin embargo, como bien señala Zunzunegui (2000), el documental de Patino no está tan lejos del filme de Berlanga. Además de los recursos propios del documental de corte realista y neutro, Queridísimos verdugos utiliza una batería de procedimientos propios del cine narrativo de ficción, aportando lecturas alternativas y desplazamientos del significado denotativo, "con la finalidad evidente de sacar a la luz aquello que tiende a ocultarse tras las meras apariencias» (Zunzunegui, 2000: 81). Entre estas técnicas destacan tanto el uso de la música extradiegética (con romances populares y canciones infantiles conviviendo con Bach y el canto gregoriano), como el complejo montaje entre las imágenes de los protagonistas y recortes de prensa, reconstrucciones, ilustraciones de libros e imágenes reales.

Los «ejecutores de sentencia» o «administradores de justicia» —como eufemísticamente se denominan a sí mismos los verdugos de Patino- poseen un toque esperpéntico que los acerca al señor Amadeo creado por Berlanga, Azcona e Isbert. En ambas películas, por ejemplo, aparece la defensa del garrote como la única forma de ejecución «con humanidad» para el reo y «dignidad y respeto» por sus restos. Y la filosofía fascista de uno de los verdugos de Patino parece más propia de una comedia berlanguiana que de un documental realista ${ }^{4}$.

Precisamente ahí radica la originalidad y la fuerza del documental Queridísimos verdugos, en la forma de sacar a la luz la veta esperpéntica como un modo de reflejar la realidad, encontrando uno «de los filones más fructíferos de la tradición cultural española», que coin-

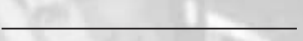

3 Uno de los últimos rostros que aparece en el filme de Patino es la fotografía, en blanco y negro de Puig Antich en un diario que titula, con letras grandes y rojas, el artículo con la palabra EJECUTADOS.

4 Bernardo Sánchez Bascuñana, decano de los verdugos españoles, enuncia los cinco mandamientos de la ley fascista: «Primero, este mundo es muy embustero. Segundo, anda muy revuelto el mundo. Tercero, comer carne de oveja cuando no hay de ternero. Cuarto, ayunar después de harto. Quinto, beber vino blanco cuando no hay tinto. Estos cinco mandamientos se encierran en dos: comer mucha carne, beber mucho vino y que le den por el saco a todo. He dicho». 
cide con la plasmación de los «modelos de indignidad plástica» que señaló Amado Alonso (Zunzunegui, 2000:82). Podemos afirmar, en consonancia con Javier Hernández, que los distintos núcleos temáticos que constituyen la arquitectura el filme no son solamente una crítica de la condena a muerte, sino que «apuntan más allá de la deslegitimación de la pena capital, incidiendo en la profunda inmoralidad del autoritarismo — franquista en este caso- que conduce a este estado de barbarie y que afecta por igual a víctimas y verdugos» (Hernández Ruiz, 2005:67).

$\mathrm{Ni}$ en El verdugo ni en la película de Patino aparecen directamente los condenados a muerte. La atención se focaliza hacia el que ejecuta la pena, dejando —en el caso de Berlanga- a los condenados, sus delitos y sus familias completamente desdibujados. En ambos filmes se ha dado la vuelta a lo habitual: el verdugo, generalmente secundario o casi invisible en la mayoría de las películas en torno a la pena de muerte, aparece aquí en primer plano, y los matices de su personalidad, sus avatares y las relaciones con sus familias son los objetos principales de atención. Pero el personaje del verdugo en la película de Berlanga no es un ser despreciable, ruin e indigno - por contraposición al reo-, sino que resulta ser el producto y la víctima de una sociedad que lo desprecia «incapaz de aceptar las consecuencias de unas normas que ella misma establece» (Maroto Laviada, 2003: 134). Amadeo es un profesional de la muerte, al que los años de profesión han borrado todo cuestionamiento moral y sólo le queda el orgullo por el trabajo bien hecho.

En el caso de Queridísimos verdugos los protagonistas son Bernardo Sánchez Bascuñana, Antonio López Sierra y Vicente López Copete, los tres pertenecientes a la última generación de verdugos que hubo en España. Sus circunstancias personales conducen de nuevo a relacionarlos con el filme de Berlanga: como José Luis, yerno del verdugo, —el personaje que interpreta Nino Manfredi-, las circunstancias cotidianas de una España hambrienta y miserable llevan a estos tres individuos a ejercer el oficio de verdugo, y como Amadeo, a causa de la reiteración del oficio han llegado al horror de la indiferencia.

Los verdugos de Patino son menos entrañables que los de Berlanga, mucho más asociales y desarraigados, cercanos al mundo de la delincuencia (Antonio López pasa años en varias cárceles antes de la sublevación franquista) y fuera de toda mitificación o sentido heroico. La misma falta de heroicidad es usada por Berlanga para la configuración de su personaje protagonista, pero el toque de ternura y bondad de Amadeo está alejado de los rasgos que definen a los miserables y marginales verdugos de Patino.

Queridísimos verdugos, es — desde el contexto histórico en que se realizó- una denuncia contra la pena de muerte, y un alegato contra el terror, la violencia y la guerra, poniendo de relieve los aspectos más duros y negros de la España profunda durante la posguerra española y la dictadura franquista. El testimonio de Patino en contra de la pena de muerte se sintetiza de forma radical en una de las imágenes que destaca Zunzunegui: «En esa mirada perdida, en esa expresión patética del rostro del padre de Pedro María Expósito, el asesino de Gandía, filmado en la tensión de la espera del posible indulto para su hijo [...] Tras esa mirada perdida habita, ya para siempre, por la fuerza del cine, la muerte en camino» (2000: 82).

Reivindicar la memoria histórica de la figura del verdugo, —un «asesino legal» en términos de Ruiz Sanz- reflejándolo como víctima y producto de una sociedad miserable y dictatorial, es una manera de luchar contra la pena de muerte en un momento histórico donde se oyen voces que la reclaman. No podemos olvidar que, en España, hasta 1995 todavía se 
contemplaban algunos supuestos para la aplicación de la condena capital pues, aunque se abolió en 1978 con la Constitución, en caso de guerra todavía podía aplicarse. En los más de veinte años de democracia este tema parecía enterrado para siempre, como un tabú que deja de serlo gracias al cine realizado en la actualidad o bien filmado durante la dictadura y reactualizado. Por ello, el cine se convierte en una poderosa herramienta para revitalizar la memoria sobre un periodo clave de nuestra historia. La pena de muerte tratada desde tres perspectivas genéricas completamente divergentes dibuja una realidad histórica donde no hay sitio para la nostalgia. La fuerza dramática del tema permite la multiplicación de miradas, de perspectivas y de tonalidades, como se puede comprobar en estas tres películas.

La memoria histórica se organiza, muchas veces, a partir de imágenes y contenidos visuales tanto de documental como de ficción. Incluso algunos sucesos históricos quedan unidos para siempre a ciertos motivos visuales que permanecen como emblemas de un tiempo pasado. Porque en la era de la información, de la comunicación de masas, del hiperconsumismo y de la construcción fragmentaria de la realidad, la memoria histórica no se fabrica a partir de decretos o legislaciones que impongan la obligación de recordar. Ni en los libros de historia que recogen, cronológicamente, un conjunto de sucesos claramente documentados. Son los relatos mediáticos —el cine, las series de televisión, las tv movies - los que ayudan a construir colectivamente una memoria histórica común de lo que se ha querido borrar del recuerdo, que es igual que borrarlo de la existencia.

Podemos concluir diciendo que desde la cercanía de la memoria y la lejanía de la historia el cine actualiza, revive y reclama un lugar para sucesos rescatados del olvido para siempre.

\section{BIBLIOGRAFÍA}

BENITO, Gloria (2006), «El garrote vil. (A propósito de Queridísimos verdugos)» en Encadenados. Revista de cine, $n^{\circ} 51-52$, diciembre. Disponible (5.06.08) en http://www.encadenados.org/n37/patino_6.htm

CORRAL, José Luis (2005), Historia de la pena de muerte, Madrid, Aguilar.

GARCÍA GRENZNER, Joana (2006), «La estafa es colar esa ficción de Salvador como recuperación de la memoria histórica» en Diagonal web. Periódico quincenal de actualidad crítica, $n^{\circ}$ 39. Disponible (31.05.08) en http://www.diagonalperiodico.net/spip.php?article2003.

GARCÍA, Rocío (2005), «Manuel Huerga: 'Puig Antich no era ni un santo ni un mártir'», El País, 27-III-2005.

HERNÁNDEZ RUIZ, Javier (2005), «Basilio Martín Patino: de la denuncia antifranquista al falso documental de los noventa" en Cine de no ficción español contemporáneo. Documental de ensayo, auto-reflexivo y performativo, Disponible (29.05.2008) en http://descargas. cervantesvirtual.com/servlet/SirveObras/68027274878268165532279/026993_0021.pdf

LE GOF, Jacques (1991), El orden de la memoria, Barcelona, Paidós.

LYTHGOE, Esteban (2004), "Consideraciones sobre la relación historia-memoria en Paul Ricoeur», Revista de Filosofía, Universidad de Chile, vol. LX, Disponible (29.05.2008) en http://www.filosofia.uchile.cl/publicaciones/revfiloso/60/pdf/lythgoe.pdf

MAROTO LAVIADA, René (2003), «El verdugo. Escenas sombrías de una España reciente» en RIVAYA, Benjamín (2003).

MONTERDE, José Enrique, SELVA MASOLIVER, Marta y SOLÀ ARGUIMBAU, Anna (2001), La representación cinematográfica de la historia, Madrid, Akal. 
PEDREÑO, José María (2004), «¿Qué es la memoria histórica?», Pueblos. Revista de Información y debate, $\mathrm{n}^{\circ} 12$.

PERALES, Francisco (1997), Luis García Berlanga, Madrid, Cátedra.

RICOEUR, Paul (2003), La memoria, la historia, el olvido, Madrid, Trotta.

RIVAYA, Benjamín (coord) (2003), Cine y pena de muerte. Diez análisis desde el derecho y la moral, Valencia, Tirant lo Blanch.

RUIZ SANZ, Mario (2003), El verdugo: un retrato satírico del asesino legal, Valencia, Tirant lo Blanch.

SÁNCHEZ BIOSCA, Vicente (2006), Cine de historia, cine de memoria. La representación y sus límites, Madrid, Cátedra.

SANZ, Carles (2004), "Reflexiones treinta años después del asesinato de Salvador Puig Antich" en Cuaderno de Pensamiento, $n^{\circ}$ 3. Disponible (30.05.2008) en http://www.soliobrera. org/pdefs/cuaderno3.pdf

www.basiliomartinpatino.com/film03.htm Disponible (30.05.2008)

www.manuelhuerga.com/salvador/ Disponible (30.05.2008)

VIZCAÍNO MARTÍNEZ, Juan Carlos (2008), «La vieja memoria reeditada: Queridísimos verdugos y El desencanto», Quaderns de cine, $n^{\circ} 2$, pp. 75-82.

ZUNZUNEGUI, Santos (2000), «Queridísimos verdugos. Memoria de tanto dolor» en Nosferatu, $n^{\circ} 32$. 